\title{
Plasma and Dietary Vitamin C Levels and risk of Gastric Cancer in the European Prospective Investigation into Cancer and Nutrition (EPIC-EURGAST).
}

Mazda Jenab ${ }^{1 *}$, Elio Riboli ${ }^{2}$, Pietro Ferrari ${ }^{1}$, Joan Sabate ${ }^{1,3}$, Nadia Slimani ${ }^{1}$, Teresa Norat ${ }^{1}$, Marlin Friesen ${ }^{1}$, Anne Tjønneland ${ }^{4}$, Anja Olsen ${ }^{4}$, Kim Overvad ${ }^{5}$, Marie-Christine Boutron-Ruault ${ }^{6}$, Françoise ClavelChapelon ${ }^{6}$, Mathilde Touvier ${ }^{6}$, Heiner Boeing ${ }^{7}$, Mandy Schulz ${ }^{7}$, Jakob Linseisen ${ }^{8}$, Gabriele Nagel ${ }^{8}$, Antonia Trichopoulou', Androniki Naska', Eleni Oikonomou', Vittorio $\mathrm{Krogh}^{10}$, Salvatore Panico ${ }^{11}$, Giovanna Masala $^{12}$, Carlotta Sacerdote ${ }^{13}$, Rosario Tumino ${ }^{14}$, Petra H. Peeters ${ }^{15}$, Mattijs E. Numans ${ }^{15}$, Hendrik B. Bueno-de-Mesquita $^{16}$, Frederike L. Bǘchner ${ }^{16}$, Eiliv Lund ${ }^{17}$, Guillem Pera ${ }^{18}$, Carmen Navarro Sanchez ${ }^{19}$, Maria-José Sánchez ${ }^{20}$, Larraitz Arriola ${ }^{21}$, Aurelio Barricarte ${ }^{22}$, José Ramón Quirós ${ }^{23}$, Göran Hallmans ${ }^{24}$, Roger Stenling ${ }^{25}$, Göran Berglund ${ }^{26}$, Sheila Bingham ${ }^{27}$, Kay-Tee $\mathrm{Khaw}^{28}$, Timothy Key ${ }^{29}$, Naomi Allen ${ }^{29}$, Fatima Carneiro ${ }^{30}$, U. Mahlke ${ }^{31}$, Guiseppe Del Giudice ${ }^{32}$, Domenico Palli ${ }^{12}$, Rudolf Kaaks ${ }^{1}$, Carlos A. Gonzalez ${ }^{18}$.

1. Nutrition and Hormones Group, IARC-WHO, Lyon, France.

2. Imperial College, London, United Kingdom.

3. Department of Nutrition, Loma Linda University, Loma Linda, CA, USA.

4. Institute of Cancer Epidemiology, Danish Cancer Society, Copenhagen, Denmark.

5. Department of Clinical Epidemiology, Aalborg Hospital, Aarhus University Hospital, Aalborg, Denmark.

6. INSERM, Institut Gustave Roussy, Villejuif, France.

7. German Institute of Human Nutrition, Potsdam-Rehbücke, Germany.

8. Division of Clinical Epidemiology, Deutsches Krebsforschungszentrum, Heidelberg, Germany.

9. Department of Hygiene and Epidemiology, Medical School, University of Athens, Greece.

10. Nutritional Epidemiology Unit, National Cancer Institute, Milan, Italy.

11. Department of Clinical and Experimental Medicine, Federico II University, Naples, Italy.

12. Molecular and Nutritional Epidemiology Unit, CSPO-Scientific Institute of Tuscany, Italy.

13. University of Turin and CPO-Piemonte, Turin, Italy.

14. Cancer Registry, Azienda Ospedaliera "Civile M.P. Arezzo", Ragusa, Italy.

15. Julius Centre for Health Sciences and Primary Care, University Medical Center, Utrecht, The Netherlands.

16. Centre for Nutrition and Health, National Institute for Public Health and the Environment, Bilthoven, The Netherlands.

17. Institute of Community Medicine, University of Tromso, Norway.

18. Department of Epidemiology, Catalan Institute of Oncology, Barcelona (ICO-IDIBELL), Spain.

19. Servicio de Epidemiología, Consejería de Sanidad y Consumo, Murcia, Spain.

20. Andalusian School of Public Health, Granada, Spain.

21. Public Health Department of Guipuzkoa, San Sebastian, Spain.

22. Public Health Institute of Navarra, Pamplona, Spain.

23. Sección Información Sanitaria, Consejería de Salud y Servicios Sanitarios de Asturias, Asturias, Spain.

24. Department of Public Health and Clinical Nutrition, Nutrition Research, Umeå University, Umeå, Sweden.

25. Department of Medical Biosciences, Pathology, Umeå University, Umeå, Sweden.

26. Department of Medical Epidemiology, Karolinska Instututet, Stockholm, Sweden.

27. MRC Dunn Human Nutrition Unit, Welcome Trust/MRC Building, Cambridge, UK.

28. Clinical Gerontology Unit, University of Cambridge, Cambrdge, UK.

29. Cancer Epidemiology Unit. University of Oxford, UK.

30. Institute of Molecular Pathology and Immunology of the University of Porto (IPATIMUP) and Medical Faculty of Porto/H.S. Joao, Porto, Portugal.

31. Institute of Pathology, Potsdam, Germany

32. IRIS Research Center, Chiron-Vaccines, Siena, Italy.

* To whom correspondence should be addressed: Jenab@iarc.fr 


\begin{abstract}
Vitamin $\mathrm{C}$ is an antioxidant and inhibitor of carcinogenic N-nitroso compound production in the stomach. Higher dietary vitamin $\mathrm{C}$ consumption is associated with decreased risk of gastric cancer (GC) in numerous case-control studies but data from prospective studies is limited, particularly so for blood measures of vitamin C. The objective of this study was to determine the association of plasma and dietary vitamin $\mathrm{C}$ levels with the risk of GC in a case-control study nested within the European Prospective Investigation into Cancer and Nutrition (EPIC), a large cohort involving 10 European countries. Using a fluorometric method, vitamin $\mathrm{C}$ was measured in pre-diagnostic plasma from $215 \mathrm{GC}$ cases (matched controls=416). Conditional logistic regression models adjusted by body mass index, total energy intake, smoking status/duration/intensity and Helicobacter pylori (Hp) infection status were used to estimate relative cancer risks. No association with GC risk was observed for dietary vitamin $\mathrm{C}$ whereas an inverse GC risk was observed in the highest versus lowest quartile of plasma vitamin $\mathrm{C}(\mathrm{OR}=0.55,95 \% \mathrm{CI}=0.31-0.97$, $\left.\mathrm{P}_{\text {trend }}=0.043\right)$ which was maintained after exclusion of cases with $\leq 2 \mathrm{yrs}$ follow-up $(\mathrm{OR}=0.40,95 \% \mathrm{CI}=0.19$ $\left.0.83, \mathrm{P}_{\text {trend }}=0.064\right)$. The inverse association was more pronounced in subjects consuming higher levels of red and processed meats, a factor that may increase endogenous N-nitroso compound production. The effect of plasma vitamin C was not different by GC anatomical sub-site (cardia/non-cardia) or histological sub-type (diffuse/intestinal) and there was no significant interaction of effect with Hp. The results of this study show, in a prospective setting, an inverse association of GC risk with high levels of plasma vitamin $\mathrm{C}$ and suggest an interaction with the intake of red and processed meats, whose consumption may elevate endogenous Nnitroso compound production.
\end{abstract}

\title{
Introduction
}

In many Western countries, the relative incidence rates for adenocarcinomas of the gastric cardia have increased [1;2]. Several environmental factors, particularly diet, are thought to be involved in the etiology of gastric cancers (GC). Out of the many dietary components that have been associated with GC risk, antioxidants tend to show the strongest protective effects, and by far the most effective of these is vitamin $\mathrm{C}$ [3]. In fact, the consumption of citrus fruits, which are rich dietary sources of vitamin $\mathrm{C}$, has been shown to be inversely associated with GC risk [3-5].

Vitamin $C$ is an important enzyme co-factor [6] and has also been suggested to have anti-proliferative and pro-apoptotic roles in vitro [6], to inhibit the growth of Helicobacter pylori (Hp) [7] and to regulate the immune response towards $\mathrm{Hp}$ infection [8]. But perhaps most importantly, vitamin $\mathrm{C}$ can quench reactive oxygen species produced in the gastric environment, thus limiting free radical-mediated damage in the gastric epithelium [9], and it can scavenge nitrite, inhibiting in vivo nitrosation and the production of carcinogenic N-nitroso compounds [10]. Normally, gastric mucosa and juice contain high levels of vitamin $\mathrm{C}$, perhaps even higher levels than in plasma [11]. But in the presence of gastric pathology, the vitamin $\mathrm{C}$ secretion into the gastric juice is affected, causing lower vitamin $\mathrm{C}$ concentrations [12]. GC patients have 
been shown to have decreased levels of blood vitamin $\mathrm{C}$, increased ph and nitrite in their gastric juice [13] and higher overall levels of oxidative stress [14]. In fact, low dietary vitamin C intake can enhance the progression of gastric dysplasia to GC [15], whereas vitamin C supplementation can slow the progression of gastric mucosal atrophy [16] and increase the regression rate of gastric pre-cancerous lesions [17].

Many case-control studies show an inverse association between dietary vitamin $\mathrm{C}$ intake and GC risk $[3 ; 4 ; 18 ; 19]$. Although the effect of diet on GC risk may differ based on the sub-site localization within the stomach or histological subtype of the cancer [20;21], few previous studies have considered these factors. In recent case-control studies, dietary vitamin $\mathrm{C}$ has been shown to have either no association with cardia GC [22-24], or to be inversely associated with both GC sub-sites [25;26] and sub-types [25;27]. Much of this disparity in results may be due to the inherent measurement errors in dietary recall instruments and biases associated with case-control study designs. In the few existing data from prospective studies, both increased dietary [28-30] and blood [15;31;32] vitamin C levels have been associated with a decreased GC risk.

Thus, the aim of this case-control study, nested within the European Prospective Investigation into Cancer and Nutrition (EPIC) cohort, was to determine the association of plasma and dietary vitamin C levels with risk of GC (as well as its sub-sites and sub-types), taking into account Hp infection status.

\section{Materials and Methods}

Study Population and Collection of Blood Samples. The rationale and methods of the EPIC study have been previously discussed in detail [33;34]. Briefly, EPIC consists of 23 centers in 10 European countries (Denmark, France, Greece, Germany, Italy, Netherlands, Norway, Spain, Sweden and United Kingdom). Between 1992 and 1998, standardized lifestyle and personal history questionnaires, anthropometric data and blood samples were collected from most participants. In addition, diet over the previous 12 months was measured at recruitment by validated country-specific questionnaires designed to ensure high compliance and better measures of local dietary habits [33;34]. Values for total energy and dietary vitamin $\mathrm{C}$ were computed using country-specific food composition tables. Data on the intake of vitamin C from dietary supplements are not available and were not assessed here.

As has been previously documented [33;34], in each of the 23 centers, blood samples of at least $20 \mathrm{~mL}$ were drawn from all participants and stored at $5-10^{\circ} \mathrm{C}$ protected from light and transported to local laboratories for processing and aliquoting. The only exceptions were the EPIC-Oxford centre (UK) where blood samples were collected from a network of general practitioners and transported to a central laboratory in Norfolk via mail, and centers in Sweden where blood was aliquoted within one hour of drawing.

In all countries, except Sweden, blood was separated into $0.5 \mathrm{~mL}$ fractions (serum, plasma, red cells and buffy coat for DNA extraction) and stored in heat-sealed straws at ultra-low temperatures $\left(-196^{\circ} \mathrm{C}\right)$ under 
liquid nitrogen. One half of all aliquots were stored at the local study centre and the other half in the central EPIC biorepository at the International Agency for Research on Cancer (IARC; Lyon, France). In Sweden, samples were stored in $-80^{\circ} \mathrm{C}$ freezers.

Short term losses of blood Vitamin C from handling, transport and storage prior to long term freezing have previously been shown to be minimal [35]. Prior to long term freezing, blood samples were not treated with compounds, such as meta-phosphoric acid, for the specific stabilization of vitamin C. Regardless, a recent study specifically on EPIC plasma samples shows that after freezing at $-196^{\circ} \mathrm{C}$ for up to 11 years, vitamin $\mathrm{C}$ can still be measured with reasonable reliability as a biomarker [36].

Follow-up for Cancer Incidence and Vital Status. Follow-up is based on population cancer registries (Denmark, Italy, Netherlands, Norway, Spain, Sweden and the United Kingdom) and other methods, such as health insurance records, pathology registries, and active contact of study subjects or next of kin (France, Germany and Greece). The follow-up period for the present study was for data reports received at IARC to the end of October 2002, representing complete follow-ups until either December 2000 or December 2001 for all centers using cancer registry data and until 2002 for France, Germany and Greece. Cancers of the stomach included cancers coded as C16 $\left(10^{\text {th }}\right.$ Revision of the International Statistical Classification of Diseases, Injury and Causes of Death). The diagnosis, tumor site classification and morphology (according to ICDO2 and Lauren classifications) of each identified cancer was confirmed and validated by an independent panel of pathologists with a representative from each EPIC country and a coordinator. The pathologist panel reviewed histological slides and/or re-cuts from the paraffin blocks and original histo-pathology reports provided by each EPIC centre.

Nested Case-Control Study Design and Selection of Study Subjects. The present study includes all GC incident cases (excluding gastric lymphomas, gastric stump cancers, other gastric non-adenocarcinoma, esophageal non-adenocarcinomas and otherwise unspecified malignant neoplasms) with available blood samples that were diagnosed after recruitment from all EPIC countries except Norway (blood samples only recently collected). Out of a total of 230 gastric adenocarcinomas and 18 adenocarcinomas of the gastroesophageal junction (GEJ) cases identified, plasma samples for 33 were of insufficient volume/quality for vitamin C analysis. Thus, the present study includes a total of 199 gastric adenocarcinomas and 16 GEJ, which are grouped together ( $\mathrm{n}$ matched controls $=416$ ) and referred to as GC. GC were also divided into three groups by anatomical sub-site: (i) cardia tumors ( $\mathrm{c}$ cases $=59$, n matched controls $=113$ ), combining tumors that reached the gastro-esophageal junction, either crossing it from below (all 16 GEJ adenocarcinomas) or not, (ii) non-cardia tumors ( $\mathrm{n}$ cases $=113, \mathrm{n}$ matched controls $=223$ ) grouping cases from other sites in the stomach and (iii) tumors from unknown or mixed sites ( $\mathrm{n}$ cases $=43, \mathrm{n}$ matched controls $=80$ ). When divided by histological sub-type, of the $215 \mathrm{GC}$ cases, 86 were classified as diffuse (n matched controls $=166)$ and 83 as intestinal (n matched controls $=163)$ histological subtypes according to 
the Lauren classification. The remainder ( $\mathrm{n}$ cases $=46, \mathrm{n}$ matched controls $=87$ ) were of unknown or mixed histological types. For each identified GC case, control subjects with available blood samples were selected from all cohort members who were alive and free of cancer (except non-melanoma skin cancer) at the time of diagnosis of the case patient. Controls were matched (1:2) by gender, age group ( \pm 2.5 years), study centre and date of blood sample collection ( \pm 45 days; to account for follow-up time and seasonality). Plasma vitamin $\mathrm{C}$ measurements could not be obtained for 14 control subjects and so they were excluded.

Laboratory Assay - Helicobacter pylori Infection Status. The methodology for the determination of Hp infection status is detailed elsewhere [5;37]. Briefly, quantification of anti-Hp antibodies in plasma of all cases and controls was done by ELISA using the lysate of the Hp CCUG strain. Briefly, various dilutions of plasma samples (starting dilution 1:200) were incubated with the Hp lysate in solid phase (1 ug/ml). After one hour and extensive washings, plates were incubated with an alkaline phosphatase-conjugated polyclonal affinity purified goat anti-human IgG (Sigma chemical Co, St Louis, MO). After three hours incubation and further washings, the enzymatic reaction was revealed by addition of p-nitrophenylphosphate as a substrate. Hp-specific IgG antibody titres were expressed as ELISA Units (EU), and were determined by interpolation relative to a standard curve constructed by a serial dilution of a standard positive control. A cut-off value of $100 \mathrm{EU}$ was defined using serum samples from individuals negative for H. pylori infection as determined by clinical, microbiological and serological assays (Western blotting). Serum samples with EU values above 100 were considered as positive for anti-H. pylori IgG antibodies. In previous experiments this assay exhibited specificity and sensitivity higher than $90 \%$.

Laboratory Assay - Vitamin C. Vitamin C measurements were performed at Addenbrookes Hospital (Cambridge, UK) using a fluorometric analysis method, previously described in detail [38]. Plasma from blood initially drawn into citrate tubes was removed from storage, thawed and then stabilized with a standardized volume of freshly prepared meta-phosphoric acid. Samples were quickly refrozen to $-70^{\circ} \mathrm{C}$ and shipped on dry ice to Addenbrookes Hospital for analysis. All samples were run in duplicate with matched case-control sets assayed in the same batch in order to minimize errors from batch to batch variations. Low (coefficient of variation=14.0\%) and high (coefficient of variation=7.4\%) concentration vitamin $\mathrm{C}$ quality control samples were run at the beginning and end of each analysis batch. Samples with more than 10\% difference between duplicates were repeated. Laboratory technicians were blinded to the case/control status of all samples. No significant between-day drift was observed.

Statistical Methods. Differences between cases and controls in mean vitamin C levels and baseline covariates were tested by paired t-tests. The correlation between dietary and plasma vitamin $\mathrm{C}$ was assessed by way of a spearman rank correlation test, adjusted for age, smoking duration/status, body mass index, total energy intake, and Hp positivity. 
Odds Ratios (OR) and 95\% confidence intervals $(95 \% \mathrm{CI})$ for $\mathrm{GC}$ in relation to plasma and dietary vitamin $\mathrm{C}$ concentrations were calculated by conditional logistic regression using the PHREG procedure (SAS statistical software, version 9, SAS Institute, Cary, NC), stratified by the case-control set. Risk estimates were computed both as "crude" (adjustment for matching variables only) and as "fully adjusted" with additional adjustments for potential confounders including total energy intake (in quartiles), body mass index (quartiles), Hp infection status (yes/no) and duration/status/intensity of smoking (variable categories: neversmokers, ex-smokers who smoked for $<10$ years, ex-smokers who smoked for $\geq 10$ years, smokers who smoke $<15 \mathrm{cig} / \mathrm{d}$, smokers who smoke between 15-25 cig/d, smokers who smoke $\geq 25 \mathrm{cig} / \mathrm{d}$, and missing). The effects of alcohol intake and the level of schooling (an indicator variable for socio-economic status) as potential confounding variables were examined, but they did not provide appreciable changes in risk estimates and were not included in the models. For both plasma and dietary vitamin $\mathrm{C}$, risk associations were examined by quartiles with cut points based on the distribution of vitamin $\mathrm{C}$ in the GC control subjects. Models similar to the above were also run with plasma and dietary vitamin $\mathrm{C}$ measurements included in the model as continuous variables with the ORs estimated for the risk related to a change in the plasma or dietary level by one standard deviation of the distribution in control subjects $(19.4 \mu \mathrm{mol} / \mathrm{L}$ for plasma and 72.9 $\mathrm{mg}$ /day for dietary vitamin C). For all models, tests for linear trend were performed using a score variable with values from 1 to 4 , consistent with the quartile grouping.

The models for plasma vitamin C were run separately for GC, as well as by anatomical sub-site (cardia / non-cardia) and histological sub-type (diffuse / intestinal). The same quartile cut points used for analysis of all GCs were used in sub-group analyses. Tests for heterogeneity were also run for comparison of results by sub-site and sub-type. As described above, for a number of reasons, some GC cases could not be classified by anatomical sub-site or histological sub-type. For comparison purposes, ORs were also calculated for these cases and matched controls, using the same methods described above.

Potential modification of the effects of vitamin $\mathrm{C}$ by gender, Hp infection status and time of follow-up of 2 years or less and more than two years was tested using the likelihood ratio test to assess the statistical significance of a linear interaction. For the assessment of interaction for time of follow-up, each case-control set was assigned the value for years of follow-up of the case. No overall significant interactions were observed for any of these variables. In order to assess the effect of time of follow-up in greater detail, analyses were also performed for plasma vitamin $\mathrm{C}$ and GC risk, excluding cases diagnosed with less than 2 years of follow-up.

Hp infection status was used as a confounding variable because of its purported association with GC risk and its potential to alter the systemic bioavailability of vitamin $\mathrm{C}$ [39] and the vitamin $\mathrm{C}$ concentration of gastric juice [40;41]. To further explore the role of Hp infection status, unmatched case-control analyses stratified by this variable using plasma vitamin $\mathrm{C}$ modeled as a continuous variable were performed by using 
unconditional logistic regression models adjusted for case-control matching variables, as well as the laboratory batch and all other variables described in the "fully adjusted" model above. In order to explore any role of smoking, a similar model to the above was used, stratified by smoking status (never, former, current, with missing in a separate category).

In order to correct for measurement errors in dietary vitamin $\mathrm{C}$ assessment, a linear calibration model was employed [42]. For this purpose, dietary vitamin $\mathrm{C}$ values derived from standardized 24-hour dietary recall measurements collected at baseline from an $8 \%$ subset of the EPIC cohort were taken as reference measurements [43]. They were linearly regressed on questionnaire measures of dietary vitamin $\mathrm{C}$ intake in order to compute a set of predicted values for all subjects [44]. The predicted values were used in the risk model to evaluate a corrected association between dietary vitamin $\mathrm{C}$ and gastric cancer on a continuous scale. The calibration model included center-specific terms, as well as a list of confounding variables identical to the "fully adjusted" model described above. A bootstrap sampling procedure with 300 repetitions was employed to compute the standard error of the corrected coefficient.

Since low levels of vitamin $\mathrm{C}$ and higher intake of red and processed meats are factors that may increase intra-gastric N-nitroso compound production, a potential interaction of effect of plasma vitamin $\mathrm{C}$ with dietary intake of red and processed meats was explored by modeling a smoothed dose-response relationship using the exposures and their interaction as continuous variables. The statistical significance of a linear interaction was assessed using the likelihood ratio test. Odds ratios were computed for different levels of plasma vitamin $\mathrm{C}$ and dietary red and processed meat intake, and the associated $95 \% \mathrm{CI}$ were assessed through a bootstrap sampling procedure with 1000 repetitions [45]. The reference category was set as low level of plasma vitamin $\mathrm{C}$ and high intake of red and processed meats. In theory, this category would be expected to show the highest production of endogenous $\mathrm{N}$-nitroso compounds in this population.

\section{Results}

Description of the Study Population. Table 1 shows the baseline characteristics and description of the study population. The mean age at recruitment of GC cases was ( \pm standard deviation) $59.3 \pm 8.2$ and controls was $59.4 \pm 8.2$ (Table 1). On average, GC cases had 3.3 years between blood donation and diagnosis. GC cases had a higher percentage of $\mathrm{Hp}$ positivity than controls, while body mass index was similar between cases and controls (Table 1).

Plasma Vitamin C. Table 2 shows the mean plasma vitamin $\mathrm{C}$ values and standard deviations in cases and controls, as well as the $\mathrm{p}$ value for difference between cases and controls for all the GC groupings. For GC, the mean plasma vitamin $C$ ( \pm standard deviation) was $39.9 \pm 25.2 \mu \mathrm{mol} / \mathrm{L}$ in cases and $41.4 \pm 19.4 \mu \mathrm{mol} / \mathrm{L}$ in controls $\left(\mathrm{P}_{\text {difference }}=0.26\right)$. Plasma vitamin $\mathrm{C}$ values of cases and controls did not differ by the follow-up period (data not shown). 
The association of plasma vitamin $\mathrm{C}$ with $\mathrm{GC}$ risk showed an inverse association which was significant in the highest versus the lowest quartile in both the crude $\left(\mathrm{OR}=0.53,95 \% \mathrm{CI}=0.31-0.90, \mathrm{P}_{\text {trend }}=0.023\right)$ and fully adjusted models $\left(\mathrm{OR}=0.55,95 \% \mathrm{CI}=0.31-0.97, \mathrm{P}_{\text {trend }}=0.043\right)$ (Table 3$)$. A significant negative association was maintained after the exclusion of cases with less than 2 years of follow-up (OR of the highest versus the lowest quartile $=0.40,95 \% \mathrm{CI}=0.19-0.83, \mathrm{P}_{\text {trend }}=0.064$; fully adjusted model).

The smoothed dose-response analysis of the interaction between plasma vitamin $\mathrm{C}$ and intake of red and processed meats showed that the decrease in GC risk with increasing plasma vitamin $\mathrm{C}$ concentration was more apparent in subjects with medium and high levels of red and processed meat intake (Table 4). The $\mathrm{p}$ value for interaction between plasma vitamin $\mathrm{C}$ levels and intake of red and processed meats was 0.058 .

Hp Infection Status. Plasma vitamin C values of the controls were not significantly different between Hp positive $(42.1 \pm 1.1 \mu \mathrm{mol} / \mathrm{L})$ and $\mathrm{Hp}$ negative $(39.4 \pm 1.8 \mu \mathrm{mol} / \mathrm{L})$. The $\mathrm{GC}$ risk association of plasma vitamin $\mathrm{C}$ based on $\mathrm{Hp}$ infection status was explored via unconditional logistic regression models with vitamin $\mathrm{C}$ modeled as a continuous variable. In the fully adjusted model, the ORs were estimated for a $19.4 \mu \mathrm{mol} / \mathrm{L}$ increment $(\mathrm{Hp}$ negative $=1.23,95 \% \mathrm{CI}=0.67-2.27$, $\mathrm{Hp}$ positive $=0.89,95 \% \mathrm{CI}=0.74-1.08)$.

Smoking Status. Plasma vitamin C values of the controls were not significantly different by smoking status, although values in never smokers $(43.5 \pm 1.1 \mu \mathrm{mol} / \mathrm{L}$; mean \pm standard error) where slightly higher than former smokers $(40.6 \pm 1.7 \mu \mathrm{mol} / \mathrm{L})$ and current smokers $(38.9 \pm 2.0 \mu \mathrm{mol} / \mathrm{L})$. The $\mathrm{GC}$ risk association of plasma vitamin $\mathrm{C}$ stratified by smoking status was explored via unconditional logistic regression models with vitamin $\mathrm{C}$ modeled as a continuous variable and ORs were calculated for a $19.4 \mu \mathrm{mol} / \mathrm{L}$ increment (never smokers $=1.13,95 \% \mathrm{CI}=0.86-1.47$; former smokers $=0.91,95 \% \mathrm{CI}=0.67-1.24$; current smokers $=0.67$, $95 \% \mathrm{CI}=0.43-1.06)$.

Dietary Vitamin C. The mean dietary vitamin C ( \pm standard deviation) was $129.5 \pm 81.6 \mathrm{mg} / \mathrm{day}$ for GC cases and $128.1 \pm 72.9 \mathrm{mg} /$ day for GC controls (Table 2). Dietary and plasma vitamin C levels were equally correlated in both the GC control subjects $(\mathrm{r}=0.18, \mathrm{p}<0.001)$ and cases $(\mathrm{r}=0.17, \mathrm{p}=0.016)$. Dietary vitamin $\mathrm{C}$ showed no significant associations with GC risk at any level of intake (Table 3). In the fully adjusted model, the OR for a $72.9 \mathrm{mg}$ /day increase in dietary vitamin $\mathrm{C}$ intake was 1.09 (95\% $\mathrm{CI}=0.90-1.33)$. Using the calibrated predicted values for dietary vitamin $\mathrm{C}$, the calibrated OR for a similar increment in daily intake was reduced to $0.95(0.66-1.37)$.

Grouping by Anatomical Sub-site and Histological Sub-type. There were no significant differences in mean plasma vitamin $\mathrm{C}$ concentrations between cases and controls by GC sub-site or sub-type (Table 2). Table 3 shows the ORs and confidence intervals for quartiles of increasing plasma vitamin C values and risk of GCs 
by anatomical sub-site and histological sub-type. The $\mathrm{p}$ value for heterogeneity between the cardia and noncardia sub-sites was 0.129 for the crude model and 0.091 for the fully adjusted model. For the diffuse versus the intestinal sub-type, the $\mathrm{p}$ value for heterogeneity was 0.455 for the crude model and 0.659 for the fully adjusted model. No statistically significant associations were observed with risk of either cardia or noncardia GCs at any quartiles of plasma vitamin C, although the direction of effect was always negative, particularly in the cardia. Similarly, no significant associations were observed with risk of either the diffuse or intestinal sub-types, at any category of plasma vitamin C. For comparison purposes, the ORs for groups of cases of unknown anatomical sub-site $(\mathrm{OR}=0.83,95 \% \mathrm{CI}=0.51-1.32)$ or unknown/mixed histological subtype $(\mathrm{OR}=0.76,95 \% \mathrm{CI}=0.46-1.25)$ were calculated for a $19.4 \mu \mathrm{mol} / \mathrm{L}$ increment in plasma vitamin $\mathrm{C}$.

\section{Discussion}

This nested case-control study is one of the largest prospective analyses of the association of plasma and dietary vitamin C levels with GC risk ever performed on Western European populations. The results show that within the EPIC cohort, higher plasma vitamin C level is associated with a decreased risk of GC, and does not appear to be limited to a particular GC anatomical sub-site or histological sub-type. In contrast, dietary vitamin $\mathrm{C}$ showed no significant association with GC risk, even after linear calibration.

Vitamin C may plausibly be involved in GC prevention by way of its potential to modulate cell growth kinetics [46], its purported antimicrobial activity against $\mathrm{Hp}$ [7;47] and its antioxidant properties [9]. These mechanisms can all directly relate to GC risk [12-14] and a potential GC protective effect of higher dietary vitamin C intake has been observed in ecological [48;49] and case-control studies [3;18;19;25-27]. Although the demonstrated effect of vitamin $\mathrm{C}$ in these studies is quite strong, dietary data from case-control studies are nonetheless affected by recall bias, while biochemical values may be affected by the presence of the disease. It is for these reasons that data from prospective studies, particularly those using blood biomarkers, are often valuable in adding to the scientific knowledge in a given area. However, in the case of the association of blood vitamin $\mathrm{C}$ levels and $\mathrm{GC}$, information from prospective studies is scarce, but existing data do show a generally inverse risk association in select European [31] and high risk Chinese populations [15;32] - although none stratified by sub-site or sub-type. In this regard, by way of its prospective design and use of both dietary and plasma vitamin $\mathrm{C}$ measures, the present study adds considerably to the degree of knowledge in the field.

Another key mechanism of vitamin $\mathrm{C}$ action is its inhibition of N-nitroso compound formation within the stomach [10;50]. In the present study, a borderline statistically significant interaction was observed between plasma vitamin $\mathrm{C}$ and dietary red and processed meats, whose higher intake is suggested to increase endogenous N-nitroso compound formation [51]. A smoothed dose-response analysis showed that the observed inverse GC risk association of higher plasma vitamin C concentration is more pronounced at higher intake levels of red and processed meats. In the future, the creation of databases concerning the level of 
dietary consumption and endogenous production of N-nitroso compounds and their precursors will allow this observation to be assessed in greater detail.

It is well known that $\mathrm{Hp}$ infection is a major $\mathrm{GC}$ risk factor [52-54] and it can interact with vitamin $\mathrm{C}$ by reducing its systemic bio-availability [39] and its concentration in gastric juice [40;41]. In the present study, Hp infection status was determined for all cases and controls. Statistical tests for interaction between Hp positivity and the association of plasma vitamin C with GC risk were not significant, perhaps because a large percentage of $\mathrm{Hp}$ positive cases (86.5\%) and controls (71.2\%). Other studies have also observed no statistically significant interactions between Vitamin C (from the diet) and Hp infection in association with GC risk [55]. In another study, Hp positivity was shown to be a strong risk factor for GC at low levels of dietary vitamin C intake, but not at higher levels [19], implying that any interaction of Hp status and vitamin $\mathrm{C}$ may depend on the level of vitamin $\mathrm{C}$. It may also pertain more to the concentration of vitamin $\mathrm{C}$ in gastric juice, since this has been shown to be significantly lower in Hp positive than Hp negative subjects, despite similar plasma vitamin $\mathrm{C}$ levels in the two groups [40]. Given the potential for Hp infection to modulate the effects of vitamin C (or vice versa), the present study explored the vitamin C-GC risk association stratifying by Hp infection status. Although the results were not statistically significant, they do show divergent GC risk associations based on $\mathrm{Hp}$ status ( $\mathrm{Hp}$ positive $\mathrm{OR}=0.89$; $\mathrm{Hp}$ negative $\mathrm{OR}=1.23$ ), likely because of the low number of Hp negative cases and controls. Together, these results suggest a need to further explore this area, ideally with better powered studies.

By way of an international effort to collect tumor samples and pathology reports the present study can differentiate between GCs based on their anatomical localization and their histological sub-type. Both of these factors may play a role in GC etiology [20;21], but have seldom been previously explored. Information from previous case-control studies is mixed with some showing either no effect in the cardia sub-site [24] or an inverse association of dietary vitamin $C$ with decreased risk of both anatomic sub-sites [25-27], while in a prospective setting, a stronger protective effect of dietary vitamin $\mathrm{C}$ has been observed in non-cardia GC [30]. An inverse association of dietary vitamin $\mathrm{C}$ with $\mathrm{GC}$ risk has also been observed to be equal in both histological sub-types [25] or to be stronger in the diffuse than in the intestinal [27]. Although in the present study, no significant associations were observed for plasma vitamin $\mathrm{C}$ by either anatomical sub-type or histological sub-site, the overall direction of effect was negative, particularly in the cardia sub-site. This is consistent with findings from a concurrent study based on the entire EPIC cohort showing a non-significant inverse association with the intake of citrus fruits, a rich source of dietary vitamin C, and risk of cardia GCs [5]. The observations of the present study may be due to either equal effect or low number of cases.

In the present study, $\mathrm{GC}$ risk was associated with plasma vitamin $\mathrm{C}$ concentration, but was not related to the level of dietary vitamin $\mathrm{C}$ intake. To some degree, this may be because of errors in food composition tables from which dietary vitamin $\mathrm{C}$ values were derived or the lack of information on vitamin $\mathrm{C}$ intake from 
dietary supplements. But it could also be due to potential measurement errors in the assessment of dietary vitamin $\mathrm{C}$ intake. In order to better account for such errors, a calibration exercise was attempted in the present study. No significant GC risk association was observed, but calibration reduced the OR estimate of dietary vitamin $\mathrm{C}$ from 1.09 to 0.95 , which is still not comparable to that obtained for plasma vitamin $\mathrm{C}$. This may be because estimation of dietary vitamin $\mathrm{C}$ does not account for factors such as efficiency of uptake from the digestive tract or availability from different foods, which may influence overall plasma vitamin $\mathrm{C}$ levels. In addition, some cases may have lower plasma vitamin $\mathrm{C}$ levels prior to clinical diagnosis because of potential endogenous consumption of vitamin $C$ by the process of tumor development $[8 ; 56]$ or possible changes in intake patterns of vitamin $\mathrm{C}$ rich foods induced by gastric discomfort from precancerous lesions. Furthermore, plasma vitamin $\mathrm{C}$ measures also reflect vitamin $\mathrm{C}$ intake derived from dietary supplements. Collectively these errors may in part account for some of the discrepancy in results observed here.

The relationship between dietary and plasma vitamin C is known to be non-linear [57]. Within a sub-group of the EPIC study [58], and elsewhere [59], it has been observed that the correlation of dietary and plasma vitamin $\mathrm{C}$ is lower at higher levels of vitamin $\mathrm{C}$ intake [58]. This suggests that the vitamin C-GC risk association may also be non-linear, and that the risk associated with dietary intakes that are lower on the plasma vitamin $\mathrm{C}$ curve may be more physiologically relevant. Although, this was explored via cubic spline flexible regression models in preliminary analyses for the present study, the results were not different from those presented here. An explanation for this may be found in data from controlled clinical studies showing that plasma vitamin $\mathrm{C}$ concentrations start to plateau at levels beyond $80 \mu \mathrm{mol} / \mathrm{L}$ and that dietary intakes above $1000 \mathrm{mg}$ /day are associated with complete plasma vitamin C saturation [57] - both of which are higher than the average values of the highest quartiles of plasma and dietary vitamin $\mathrm{C}$ observed here. This suggests that in the present study, the vitamin $\mathrm{C}$ concentrations associated with an inverse GC risk are likely mostly in the linear part of the vitamin $\mathrm{C}$ pharmacokinetics curve, prior to any plateau of plasma values.

A potential limitation of the present study is the relatively short follow-up time. The mean number of years from blood donation to diagnosis was 3.3 years. Cases identified within a short period of time after the start of the study may have been experiencing symptoms leading to dietary changes and hence alterations in blood vitamin $\mathrm{C}$ levels. Here, interaction tests were run in order to assess if data in the first years of follow-up affected the association of plasma vitamin $\mathrm{C}$ and cancer risk. However, no statistically significant interactions were observed and elimination of the cases diagnosed in the first two years of follow-up did not change the observed negative association, suggesting that the short follow-up time is likely not a major factor in this investigation.

In summary, these results based on the prospective EPIC study, are in line with earlier observations that higher plasma vitamin $\mathrm{C}$ levels are inversely associated with GC risk. Further studies are also necessary to determine the mechanisms of vitamin $\mathrm{C}$ action and any potential interactions with Hp infection and smoking. 


\section{Acknowledgements}

We thank the members of the pathologist panel for their valuable work: Dr Roger Stenling, Umea, Sweden; Dr Johan Offerhaus, Amsterdam The Netherlands; Dr Vicki Save, Cambridge, United Kingdom, Dr Julio Torrado, San Sebastian, Spain; Dr. Gabriella Nesi, Firenze, Italy; Dr. U Mahlke, Postdam, Germany; Dr Hendrik Bläker, Heildelberg; Germany; Dr Claus Fenger, Denmark and Dr. Dimitrious Roukos, Ioannina, Greece, for his collaboration in the collection of pathological material and Catia Moutinho, Porto, Portugal, for her technical work in the preparation of pathological material.

Specific study results of the nested case-control study within EPIC (EUR-GAST) were obtained with financial support from the FP5 of the European Commission (QLG1-CT-2001-01049).

The EPIC study was funded by "Europe Against Cancer" Programme of the European Commission (SANCO); Ligue contre le Cancer (France); Société 3M (France); Mutuelle Générale de l'Education Nationale; Institut National de la Santé et de la Recherche Médicale (INSERM); German Cancer Aid; German Cancer Research Center; German Federal Ministry of Education and Research; Danish Cancer Society; Health Research Fund (FIS) of the Spanish Ministry of Health (RCESP-C03/09); the participating regional governments and institutions of Spain; The ISCIII Red de Centro RCESP (C03/09); Cancer Research UK; Medical Research Council, UK; the Stroke Association, UK; British Heart Foundation; Department of Health, UK; Food Standards Agency, UK; the Wellcome Trust, UK; Greek Ministry of Health; Greek Ministry of Education; Italian Association for Research on Cancer; Italian National Research Council; Compagnia di San Paolo; Dutch Ministry of Public Health, Welfare and Sports; Dutch Ministry of Health; Dutch Prevention Funds; LK Research Funds; Dutch ZON (Zorg Onderzoek Nederland); World Cancer Research Fund (WCRF); Swedish Cancer Society; Swedish Scientific Council; Regional Government of Skane, Sweden; Norwegian Cancer Society.

\section{References}

1. Devesa,S.S., Blot,W.J., and Fraumeni,J.F., Jr. (1998) Changing patterns in the incidence of esophageal and gastric carcinoma in the United States. Cancer, 83, 2049-2053.

2. Botterweck,A.A., Schouten,L.J., Volovics,A., Dorant,E., and van Den Brandt,P.A. (2000) Trends in incidence of adenocarcinoma of the oesophagus and gastric cardia in ten European countries. Int $J$ Epidemiol, 29, 645-654.

3. World Cancer Research Fund and American Institute for Cancer Research. Food Research and the Prevention of Cancer: A Global Perspective. 1997. Washington, D.C., World Cancer Research Fund; American Institute for Cancer Research.

4. Riboli,E. and Norat,T. (2003) Epidemiologic evidence of the protective effect of fruit and vegetables on cancer risk. Am J Clin Nutr, 78, 559S-569S. 
5. Gonzalez,C.A., Pera,G., Agudo,A., Bueno-De-Mesquita,H.B., Ceroti,M., Boeing,H., Schulz,M., Del Giudice,G., Plebani,M., Carneiro,F., Berrino,F., Sacerdote,C., Tumino,R., Panico,S., Berglund,G., Siman,H., Hallmans,G., Stenling,R., Martinez,C., Dorronsoro,M., Barricarte,A., Navarro,C., Quiros,J.R., Allen,N., Key,T.J., Bingham,S., Day,N.E., Linseisen,J., Nagel,G., Overvad,K., Jensen,M.K., Olsen,A., Tjonneland,A., Buchner,F.L., Peeters,P.H., Numans,M.E., ClavelChapelon,F., Boutron-Ruault,M.C., Roukos,D., Trichopoulou,A., Psaltopoulou,T., Lund,E., Casagrande,C., Slimani,N., Jenab,M., and Riboli,E. (2006) Fruit and vegetable intake and the risk of stomach and oesophagus adenocarcinoma in the European Prospective Investigation into Cancer and Nutrition (EPIC-EURGAST). Int J Cancer, 118, 2559-2566.

6. Halliwell,B. (2001) Vitamin C and genomic stability. Mutat Res, 475, 29-35.

7. Jarosz,M., Dzieniszewski,J., Dabrowska-Ufniarz,E., Wartanowicz,M., Ziemlanski,S., and Reed,P.I. (1998) Effects of high dose vitamin C treatment on Helicobacter pylori infection and total vitamin C concentration in gastric juice. Eur J Cancer Prev, 7, 449-454.

8. Zhang,Z.W. and Farthing,M.J. (2005) The roles of vitamin C in Helicobacter pylori associated gastric carcinogenesis. Chin J Dig Dis, 6, 53-58.

9. Drake,I.M., Davies,M.J., Mapstone,N.P., Dixon,M.F., Schorah,C.J., White,K.L., Chalmers,D.M., and Axon,A.T. (1996) Ascorbic acid may protect against human gastric cancer by scavenging mucosal oxygen radicals. Carcinogenesis, 17, 559-562.

10. Mirvish,S.S. (1994) Experimental evidence for inhibition of N-nitroso compound formation as a factor in the negative correlation between vitamin $\mathrm{C}$ consumption and the incidence of certain cancers. Cancer Res, 54, 1948s-1951s.

11. Schorah,C.J., Sobala,G.M., Sanderson,M., Collis,N., and Primrose,J.N. (1991) Gastric juice ascorbic acid: effects of disease and implications for gastric carcinogenesis. Am J Clin Nutr, 53, 287S-293S.

12. Zhang,Z.W., Patchett,S.E., Perrett,D., Katelaris,P.H., Domizio,P., and Farthing,M.J. (1998) The relation between gastric vitamin $\mathrm{C}$ concentrations, mucosal histology, and CagA seropositivity in the human stomach. Gut, 43, 322-326.

13. Kodama,K., Sumii,K., Kawano,M., Kido,T., Nojima,K., Sumii,M., Haruma,K., Yoshihara,M., and Chayama,K. (2003) Gastric juice nitrite and vitamin C in patients with gastric cancer and atrophic gastritis: is low acidity solely responsible for cancer risk? Eur J Gastroenterol Hepatol, 15, 987-993.

14. Khanzode,S.S., Khanzode,S.D., and Dakhale,G.N. (2003) Serum and plasma concentration of oxidant and antioxidants in patients of Helicobacter pylori gastritis and its correlation with gastric cancer. Cancer Lett, 195, 27-31.

15. You,W.C., Zhang,L., Gail,M.H., Chang,Y.S., Liu,W.D., Ma,J.L., Li,J.Y., Jin,M.L., Hu,Y.R., Yang,C.S., Blaser,M.J., Correa,P., Blot,W.J., Fraumeni,J.F., Jr., and Xu,G.W. (2000) Gastric dysplasia and gastric cancer: Helicobacter pylori, serum vitamin C, and other risk factors. $J$ Natl Cancer Inst, 92, 1607-1612. 
16. Sasazuki,S., Sasaki,S., Tsubono,Y., Okubo,S., Hayashi,M., Kakizoe,T., and Tsugane,S. (2003) The effect of 5-year vitamin $\mathrm{C}$ supplementation on serum pepsinogen level and Helicobacter pylori infection. Cancer Sci, 94, 378-382.

17. Correa,P., Fontham,E.T., Bravo,J.C., Bravo,L.E., Ruiz,B., Zarama,G., Realpe,J.L., Malcom,G.T., Li,D., Johnson,W.D., and Mera,R. (2000) Chemoprevention of gastric dysplasia: randomized trial of antioxidant supplements and anti-helicobacter pylori therapy. J Natl Cancer Inst, 92, 1881-1888.

18. Lagiou,P., Samoli,E., Lagiou,A., Peterson,J., Tzonou,A., Dwyer,J., and Trichopoulos,D. (2004) Flavonoids, vitamin $\mathrm{C}$ and adenocarcinoma of the stomach. Cancer Causes Control, 15, 67-72.

19. Kim,D.S., Lee,M.S., Kim,Y.S., Kim,D.H., Bae,J.M., Shin,M.H., and Ahn,Y.O. (2005) Effect modification by vitamin $\mathrm{C}$ on the relation between gastric cancer and Helicobacter pylori. Eur $J$ Epidemiol, 20, 67-71.

20. Mayne,S.T. and Navarro,S.A. (2002) Diet, obesity and reflux in the etiology of adenocarcinomas of the esophagus and gastric cardia in humans. J Nutr, 132, 3467S-3470S.

21. Correa,P. and Shiao,Y.H. (1994) Phenotypic and genotypic events in gastric carcinogenesis. Cancer Res, 54, 1941s-1943s.

22. Kabat,G.C., Ng,S.K., and Wynder,E.L. (1993) Tobacco, alcohol intake, and diet in relation to adenocarcinoma of the esophagus and gastric cardia. Cancer Causes Control, 4, 123-132.

23. Zhang,Z.F., Kurtz,R.C., Yu,G.P., Sun,M., Gargon,N., Karpeh,M., Jr., Fein,J.S., and Harlap,S. (1997) Adenocarcinomas of the esophagus and gastric cardia: the role of diet. Nutr Cancer, 27, 298-309.

24. Terry,P., Lagergren,J., Ye,W., Nyren,O., and Wolk,A. (2000) Antioxidants and cancers of the esophagus and gastric cardia. Int J Cancer, 87, 750-754.

25. Ekstrom,A.M., Serafini,M., Nyren,O., Hansson,L.E., Ye,W., and Wolk,A. (2000) Dietary antioxidant intake and the risk of cardia cancer and noncardia cancer of the intestinal and diffuse types: a population-based case-control study in Sweden. Int J Cancer, 87, 133-140.

26. Mayne,S.T., Risch,H.A., Dubrow,R., Chow,W.H., Gammon,M.D., Vaughan,T.L., Farrow,D.C., Schoenberg,J.B., Stanford,J.L., Ahsan,H., West,A.B., Rotterdam,H., Blot,W.J., and Fraumeni,J.F., Jr. (2001) Nutrient intake and risk of subtypes of esophageal and gastric cancer. Cancer Epidemiol Biomarkers Prev, 10, 1055-1062.

27. Harrison,L.E., Zhang,Z.F., Karpeh,M.S., Sun,M., and Kurtz,R.C. (1997) The role of dietary factors in the intestinal and diffuse histologic subtypes of gastric adenocarcinoma: a case-control study in the U.S. Cancer, 80, 1021-1028.

28. Zheng,W., Sellers,T.A., Doyle,T.J., Kushi,L.H., Potter,J.D., and Folsom,A.R. (1995) Retinol, antioxidant vitamins, and cancers of the upper digestive tract in a prospective cohort study of postmenopausal women. Am J Epidemiol, 142, 955-960.

29. Botterweck,A.A., van Den Brandt,P.A., and Goldbohm,R.A. (2000) Vitamins, carotenoids, dietary fiber, and the risk of gastric carcinoma: results from a prospective study after 6.3 years of follow-up. Cancer, 88, 737-748. 
30. Nouraie,M., Pietinen,P., Kamangar,F., Dawsey,S.M., Abnet,C.C., Albanes,D., Virtamo,J., and Taylor,P.R. (2005) Fruits, vegetables, and antioxidants and risk of gastric cancer among male smokers. Cancer Epidemiol Biomarkers Prev, 14, 2087-2092.

31. Stahelin,H.B., Gey,K.F., Eichholzer,M., Ludin,E., Bernasconi,F., Thurneysen,J., and Brubacher,G. (1991) Plasma antioxidant vitamins and subsequent cancer mortality in the 12-year follow-up of the prospective Basel Study. Am J Epidemiol, 133, 766-775.

32. Yuan,J.M., Ross,R.K., Gao,Y.T., Qu,Y.H., Chu,X.D., and Yu,M.C. (2004) Prediagnostic levels of serum micronutrients in relation to risk of gastric cancer in Shanghai, China. Cancer Epidemiol Biomarkers Prev, 13, 1772-1780.

33. Riboli,E. and Kaaks,R. (1997) The EPIC Project: rationale and study design. European Prospective Investigation into Cancer and Nutrition. Int J Epidemiol, 26 Suppl 1, S6-14.

34. Riboli,E., Hunt,K.J., Slimani,N., Ferrari,P., Norat,T., Fahey,M., Charrondiere,U.R., Hemon,B., Casagrande,C., Vignat,J., Overvad,K., Tjonneland,A., Clavel-Chapelon,F., Thiebaut,A., Wahrendorf,J., Boeing,H., Trichopoulos,D., Trichopoulou,A., Vineis,P., Palli,D., Bueno-DeMesquita,H.B., Peeters,P.H., Lund,E., Engeset,D., Gonzalez,C.A., Barricarte,A., Berglund,G., Hallmans,G., Day,N.E., Key,T.J., Kaaks,R., and Saracci,R. (2002) European Prospective Investigation into Cancer and Nutrition (EPIC): study populations and data collection. Public Health Nutr, 5, 1113-1124.

35. Key,T., Oakes,S., Davey,G., Moore,J., Edmond,L.M., McLoone,U.J., and Thurnham,D.I. (1996) Stability of vitamins A, C, and E, carotenoids, lipids, and testosterone in whole blood stored at 4 degrees $\mathrm{C}$ for 6 and 24 hours before separation of serum and plasma. Cancer Epidemiol Biomarkers Prev, 5, 811-814.

36. Jenab,M., Bingham,S., Ferrari,P., Friesen,M.D., Al Delaimy,W.K., Luben,R., Wareham,N., Khaw,K.T., and Riboli,E. (2005) Long-term cryoconservation and stability of vitamin C in serum samples of the European prospective investigation into cancer and nutrition. Cancer Epidemiol Biomarkers Prev, 14, 1837-1840.

37. Palli,D., Masala,G., Del Giudice,G., Plebani,M., Basso,D., Berti,D., Numans,M.E., Ceroti,M., Peeters,P.H.M., Bueno de Mesquita,H.B., Clavel-Chapelon,F., Krogh,V., Saieva,C., Vineis,P., Panico,S., Tumino,R., Siman,H., Berglund,G., Hallmans,G., Martinez,C., Quiros,J.R., Navarro,C., Key,T., Bingham,S., Boeing,H., Linseisen,J., Overvad,K., Tjonneland,A., Trichoupoulou,A., Pera,G., Nesi,G., Carneiro,F., Riboli,E., and Gonzalez,C.A. (2006) CagA + Helicobacter pylori infection, Pepsinogen levels and Gastric Cancer risk in the European Prospective Investigation Into Cancer and Nutrition (EPIC-EUR-GAST). Gastroenterology, In Press.

38. Vuilleumier,J. and Keck,E. (1989) Fluorometric Assay of Vitamin C in Biologic Materials Using a Centrifugal Analyser with Fluorescence Attachment. J.Micronutrient Analysis, 5, 25-34.

39. Woodward,M., Tunstall-Pedoe,H., and McColl,K. (2001) Helicobacter pylori infection reduces systemic availability of dietary vitamin C. Eur J Gastroenterol Hepatol, 13, 233-237. 
40. Banerjee,S., Hawksby,C., Miller,S., Dahill,S., Beattie,A.D., and McColl,K.E. (1994) Effect of Helicobacter pylori and its eradication on gastric juice ascorbic acid. Gut, 35, 317-322.

41. Fraser,A.G. and Woollard,G.A. (1999) Gastric juice ascorbic acid is related to Helicobacter pylori infection but not ethnicity. J Gastroenterol Hepatol, 14, 1070-1073.

42. Kaaks,R., Riboli,E., and van Staveren,W. (1995) Calibration of dietary intake measurements in prospective cohort studies. Am J Epidemiol, 142, 548-556.

43. Slimani,N., Kaaks,R., Ferrari,P., Casagrande,C., Clavel-Chapelon,F., Lotze,G., Kroke,A., Trichopoulos,D., Trichopoulou,A., Lauria,C., Bellegotti,M., Ocke,M.C., Peeters,P.H., Engeset,D., Lund,E., Agudo,A., Larranaga,N., Mattisson,I., Andren,C., Johansson,I., Davey,G., Welch,A.A., Overvad,K., Tjonneland,A., Van Staveren,W.A., Saracci,R., and Riboli,E. (2002) European Prospective Investigation into Cancer and Nutrition (EPIC) calibration study: rationale, design and population characteristics. Public Health Nutr, 5, 1125-1145.

44. Ferrari,P., Al Delaimy,W.K., Slimani,N., Boshuizen,H.C., Roddam,A., Orfanos,P., Skeie,G., Rodriguez-Barranco,M., Thiebaut,A., Johansson,G., Palli,D., Boeing,H., Overvad,K., and Riboli,E. (2005) An approach to estimate between- and within-group correlation coefficients in multicenter studies: plasma carotenoids as biomarkers of intake of fruits and vegetables. Am J Epidemiol, 162, 591-598.

45. Efron,B. and Tibshirani,R. (1993) An introduction to the bootstrap. Chapman \& Hall, New York.

46. Zhang,Z.W., Abdullahi,M., and Farthing,M.J. (2002) Effect of physiological concentrations of vitamin C on gastric cancer cells and Helicobacter pylori. Gut, 50, 165-169.

47. Akyon,Y. (2002) Effect of antioxidants on the immune response of Helicobacter pylori. Clin Microbiol Infect, 8, 438-441.

48. Kneller,R.W., Guo,W.D., Hsing,A.W., Chen,J.S., Blot,W.J., Li,J.Y., Forman,D., and Fraumeni,J.F., Jr. (1992) Risk factors for stomach cancer in sixty-five Chinese counties. Cancer Epidemiol Biomarkers Prev, 1, 113-118.

49. Ocke,M.C., Kromhout,D., Menotti,A., Aravanis,C., Blackburn,H., Buzina,R., Fidanza,F., Jansen,A., Nedeljkovic,S., Nissienen,A., and . (1995) Average intake of anti-oxidant (pro)vitamins and subsequent cancer mortality in the 16 cohorts of the Seven Countries Study. Int J Cancer, 61, 480484.

50. Bartsch,H., Ohshima,H., and Pignatelli,B. (1988) Inhibitors of endogenous nitrosation. Mechanisms and implications in human cancer prevention. Mutat Res, 202, 307-324.

51. Bingham,S.A., Hughes,R., and Cross,A.J. (2002) Effect of white versus red meat on endogenous Nnitrosation in the human colon and further evidence of a dose response. $J$ Nutr, 132, 3522S-3525S.

52. Parsonnet,J., Friedman,G.D., Vandersteen,D.P., Chang,Y., Vogelman,J.H., Orentreich,N., and Sibley,R.K. (1991) Helicobacter pylori infection and the risk of gastric carcinoma. $N$ Engl J Med, 325, $1127-1131$. 
53. Hansson,L.E., Engstrand,L., Nyren,O., Evans,D.J., Jr., Lindgren,A., Bergstrom,R., Andersson,B., Athlin,L., Bendtsen,O., and Tracz,P. (1993) Helicobacter pylori infection: independent risk indicator of gastric adenocarcinoma. Gastroenterology, 105, 1098-1103.

54. IARC Working Group on the Evaluation of Carcinogenic Risks to Humans (1994) Schistosomes, liver flukes and Helicobacter pylori. IARC Working Group on the Evaluation of Carcinogenic Risks to Humans. Lyon, 7-14 June 1994. IARC Monogr Eval Carcinog Risks Hum, 61, 1-241.

55. Lunet,N. and Barros,H. (2004) Does vitamin C dietary intake modify the association between Helicobacter pylori infection and gastric cancer? Eur J Epidemiol, 19, 1061-1062.

56. Ernst,P. (1999) Review article: the role of inflammation in the pathogenesis of gastric cancer. Aliment.Pharmacol Ther, 13 Suppl 1, 13-18.

57. Levine,M., Conry-Cantilena,C., Wang,Y., Welch,R.W., Washko,P.W., Dhariwal,K.R., Park,J.B., Lazarev,A., Graumlich,J.F., King,J., and Cantilena,L.R. (1996) Vitamin C pharmacokinetics in healthy volunteers: evidence for a recommended dietary allowance. Proc Natl Acad Sci U S A, 93, 3704-3709.

58. Boeing,H., Bohlscheid-Thomas,S., Voss,S., Schneeweiss,S., and Wahrendorf,J. (1997) The relative validity of vitamin intakes derived from a food frequency questionnaire compared to 24-hour recalls and biological measurements: results from the EPIC pilot study in Germany. European Prospective Investigation into Cancer and Nutrition. Int J Epidemiol, 26 Suppl 1, S82-S90.

59. VanderJagt,D.J., Garry,P.J., and Bhagavan,H.N. (1987) Ascorbic acid intake and plasma levels in healthy elderly people. Am J Clin Nutr, 46, 290-294. 
Table 1: Baseline characteristics and description of the study population.

\begin{tabular}{|c|c|c|}
\hline Gastric Cancer & $\begin{array}{l}\text { Cases } \\
n=215\end{array}$ & $\begin{array}{c}\text { Controls } \\
n=416\end{array}$ \\
\hline Age at Recruitment & $59.3 \pm 8.2$ & $59.4 \pm 8.2$ \\
\hline Age at Diagnosis & $62.7 \pm 8.6$ & NA \\
\hline $\begin{array}{r}\text { Mean Number of Years Between Blood Donation and } \\
\text { Diagnosis }\end{array}$ & $3.3 \pm 2.2$ & NA \\
\hline Percent Hp Positive & 86.5 & 70.9 \\
\hline Body Mass Index & $26.5 \pm 3.9$ & $26.5 \pm 4.2$ \\
\hline Number of Males & 119 & 230 \\
\hline Number of Females & 96 & 186 \\
\hline
\end{tabular}

Grouping by Anatomical Sub-site:

Cardia, no. of subjects $\quad 59 \quad 113$

Non-cardia, no. of subjects $\quad 113 \quad 223$

Unknown or Mixed Sub-site, no. of subjects $\quad 43 \quad 80$

Grouping by Histological Sub-type:

Diffuse, no. of subjects $\quad 86 \quad 166$

Intestinal, no. of subjects $\quad 83 \quad 163$

Unknown or Mixed Sub-type, no. of subjects $\quad 46 \quad 87$

\begin{abstract}
Values are either means \pm standard deviation, or number of subjects, except for Hp positivity which is given as an overall percentage, as indicated. For gastric cancers, distribution of cases/controls by country: France $=3 / 6$, Germany $=30 / 60$, Greece $=12 / 23$, Italy $=43 / 84$, Netherlands $=18 / 35$, Spain $=27 / 52$, Sweden $=54 / 102$, United Kingdom=28/54.
\end{abstract}


Table 2: Means, Standard Deviation and Distribution of Plasma Vitamin C Levels Amongst Cases and Controls in Gastric Cancers and Adenocarcinoma of the Esophagus.

\begin{tabular}{|c|c|c|c|c|c|c|c|}
\hline & \multicolumn{2}{|r|}{ Cases } & \multicolumn{2}{|c|}{ Controls } & \multirow{2}{*}{$\begin{array}{c}\text { P for Difference } \\
\text { in Mean } \\
\text { Vitamin C } \\
\text { Levels } \uparrow\end{array}$} & \multicolumn{2}{|c|}{$\begin{array}{c}5^{\text {th }}-95^{\text {th }} \text { Percentile Distribution of } \\
\text { Vitamin C** }\end{array}$} \\
\hline & Number & $\begin{array}{c}\text { Mean Vitamin C } \\
\text { Level } \pm \text { Stdev * }\end{array}$ & Number & $\begin{array}{c}\text { Mean Vitamin C } \\
\text { Level } \pm \text { Stdev * }\end{array}$ & & Cases & Controls \\
\hline \multicolumn{8}{|l|}{ Gastric Cancers } \\
\hline $\begin{array}{r}\text { Plasma Vitamin C } \\
(\mu \mathrm{mol} / \mathrm{L})^{*}\end{array}$ & 215 & $39.9 \pm 25.2$ & 416 & $41.5 \pm 19.4$ & 0.26 & $11.0-82.0$ & $12.0-75.0$ \\
\hline $\begin{array}{r}\text { Dietary Vitamin C } \\
\text { (mg/day)* }\end{array}$ & 215 & $129.5 \pm 81.6$ & 416 & $128.1 \pm 72.9$ & 0.67 & $41.0-279.1$ & $42.7-248.7$ \\
\hline
\end{tabular}

Grouping of Gastric Cancers by Anatomical Sub-Site - Plasma Vitamin C ( $\mu \mathrm{mol} / \mathrm{L})$

\begin{tabular}{|c|c|c|c|c|c|c|c|}
\hline $\begin{array}{l}\text { Cardia Gastric } \\
\text { Cancers }\end{array}$ & 59 & $37.0 \pm 17.9$ & 113 & $40.7 \pm 18.3$ & 0.08 & $10.0-79.0$ & $15.0-77.0$ \\
\hline $\begin{array}{l}\text { Non-cardia Gastric } \\
\text { Cancers }\end{array}$ & 113 & $42.5 \pm 27.7$ & 223 & $42.2 \pm 20.6$ & 0.88 & $14.0-88.0$ & $12.0-76.0$ \\
\hline
\end{tabular}

Grouping of Gastric Cancers by Histological Sub-Type - Plasma Vitamin C ( $\mu \mathrm{mol} / \mathrm{L})$

\begin{tabular}{lcccccc}
$\begin{array}{l}\text { Diffuse Gastric } \\
\text { Cancers }\end{array}$ & 86 & $43.8 \pm 31.7$ & 166 & $44.6 \pm 20.3$ & 0.81 & $9.0-88.0$ \\
$\begin{array}{l}\text { Intestinal Gastric } \\
\text { Cancers }\end{array}$ & 83 & $37.9 \pm 20.0$ & 163 & $40.6 \pm 18.7$ & 0.25 & $10.0-82.0$ \\
\hline
\end{tabular}

* Values are means \pm standard deviations.

** Values represent the lowest and highest plasma vitamin $\mathrm{C}$ values of all controls in each cancer grouping, in the $5^{\text {th }}$ and $95^{\text {th }}$ percentiles respectively.

$\uparrow$ Two sided $p$ values, paired $t$ test, given for a difference between cases and controls. 
Table 3: Odds ratios for quartiles of increasing levels of plasma and dietary vitamin C and risk of gastric cancers.

\begin{tabular}{|c|c|c|c|c|c|c|}
\hline \multirow[b]{2}{*}{ Gastric Cancer } & \multirow[b]{2}{*}{ Ref } & \multicolumn{2}{|c|}{$\begin{array}{l}\text { Odds Ratios (OR) for Quartiles of } \\
\text { Plasma or Dietary Vitamin C Levels }\end{array}$} & \multirow[t]{2}{*}{ 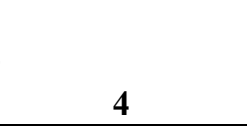 } & \multirow[b]{2}{*}{ Ptrend +} & \multirow{2}{*}{$\begin{array}{c}\text { OR of One Std. } \\
\text { Deviation } \\
\text { Increase * }\end{array}$} \\
\hline & & 2 & 3 & & & \\
\hline Plasma Vitamin C & $<29.0$ & $\geq 29.0-<40.0$ & $\geq 40.0-<51.0$ & $\geq 51.0 \mu \mathrm{mol} / \mathrm{L}$ & & $19.4 \mu \mathrm{mol} / \mathrm{L}$ \\
\hline Cases/Controls & $70 / 101$ & $46 / 98$ & $54 / 112$ & $45 / 105$ & & \\
\hline Mean $(\mu \mathrm{mol} / \mathrm{L})^{* *}$ & $19.1 \pm 0.7$ & $34.1 \pm 0.3$ & $44.9 \pm 0.3$ & $66.3 \pm 1.6$ & & \\
\hline Crude & 1.00 & $0.64(0.40-1.03)$ & $0.67(0.42-1.05)$ & $0.53(0.31-0.90)$ & 0.023 & $0.90(0.75-1.08)$ \\
\hline Fully Adjusted & 1.00 & $0.73(0.43-1.22)$ & $0.70(0.43-1.14)$ & $0.55(0.31-0.97)$ & 0.043 & $0.93(0.77-1.12)$ \\
\hline Diet Vitamin C & $<78.0$ & $\geq 78.0-<111.5$ & $\geq 111.5-<160.0$ & $\geq 160.0 \mathrm{mg} /$ day & & $72.9 \mathrm{mg} /$ day \\
\hline Cases/Controls & $61 / 104$ & $45 / 104$ & $56 / 101$ & $53 / 107$ & & \\
\hline Mean (mg/day)** & $55.8 \pm 1.5$ & $96.9 \pm 1.0$ & $134.7 \pm 1.4$ & $223.3 \pm 6.9$ & & \\
\hline Crude & 1.00 & $0.75(0.46-1.21)$ & $0.94(0.59-1.49)$ & $0.85(0.53-1.38)$ & 0.719 & $1.02(0.86-1.22)$ \\
\hline Fully Adjusted & 1.00 & $0.77(0.45-1.30)$ & $0.94(0.57-1.58)$ & $1.02(0.60-1.74)$ & 0.769 & $1.09(0.90-1.33)$ \\
\hline
\end{tabular}

Grouping of Gastric Cancers by Anatomical Sub-Site

Plasma Vitamin C

$<29.0 \geq 29.0-<40.0 \geq 40.0-<51.0$

$\geq 51.0 \mu \mathrm{mol} / \mathrm{L}$

$19.4 \mu \mathrm{mol} / \mathrm{L}$

Cardia

Cases/Controls

$17 / 29$

$16 / 28$

$16 / 29$

$10 / 27$

Crude

1.00

$0.84(0.35-2.01)$

$0.79(0.32-1.96)$

$0.47(0.16-1.40)$

0.209

$0.71(0.47-1.07)$

Fully Adjusted

1.00

$0.74(0.25-2.16)$

$0.59(0.21-1.66)$

$0.36(0.10-1.33)$

0.118

$0.65(0.40-1.06)$

Non-cardia

Cases/Controls

$35 / 54$

$19 / 52$

$34 / 57$

$25 / 60$

Crude

1.00

$0.53(0.26-1.08)$

$0.91(0.49-1.68)$

$0.57(0.28-1.18)$

0.334

$1.02(0.81-1.29)$

Fully Adjusted

1.00

$0.64(0.30-1.39)$

$1.01(0.51-2.03)$

$0.63(0.28-1.42)$

0.520

$1.06(0.82-1.37)$

Grouping of Gastric Cancers by Histological Sub-Type

Plasma Vitamin C $<29.0 \quad \geq 29.0-<40.0 \quad \geq 40.0-<51.0 \quad \geq 51.0 \mu \mathrm{mol} / \mathrm{L}$

$19.4 \mu \mathrm{mol} / \mathrm{L}$

Diffuse

Cases/Controls

Crude

Fully Adjusted

$27 / 30$

$17 / 44$

$21 / 43$

$21 / 49$

1.00

$0.42(0.20-0.91)$

1.00

$0.50(0.18-1.38)$

$0.55(0.27-1.14)$

$0.65(0.25-1.66)$

$19 / 51$

$16 / 38$

\section{Cases/Controls}

Crude

$26 / 42$

$22 / 32$

$1.02(0.49-2.12)$

$0.58(0.28-1.22)$

$1.21(0.53-2.75)$

$0.58(0.26-1.32)$

1.00

$0.58(0.24-1.40)$

0.101

$0.83(0.61-1.13)$

$0.59(0.20-1.73)$

0.138

$0.85(0.59-1.21)$

$\S$ Values are ORs and 95\% confidence intervals derived from models described above based on quartiles of plasma levels of vitamin $\mathrm{C}$ for GC and GC sub-group analyses, and quartiles of dietary vitamin C for GC.

+ $\mathrm{P}$ of $\chi^{2}$ test for trend using a continuous variable with $1 \mathrm{df}$.

* Values are ORs (95\% confidence intervals), derived from models as described above, for a risk associated with an increment in vitamin C level equal to the standard deviation of the controls for GCs (Plasma: $19.4 \mu \mathrm{mol} / \mathrm{L}$; Diet:72.9 mg/day).

** Values are means \pm standard error calculated based on the control subjects in each quartile of the respective variable. 
Table 4: Odds ratios for a smoothed dose response analysis of the interaction of increasing levels of plasma vitamin $\mathrm{C}$ and dietary intake of red and processed meats.

OR (95\% CI) §

Dietary Red and Processed Meat Intake Level

Plasma Vitamin C

$(\mu \mathrm{mol} / \mathrm{L})$

\begin{tabular}{ccc}
$\begin{array}{c}\text { High } \\
\geq 95.0\end{array}$ & $\begin{array}{c}\text { (g/day) } \\
\text { Medium } \\
\geq 55.6-<95.0\end{array}$ & $\begin{array}{c}\text { Low } \\
<55.6\end{array}$ \\
\hline 1.00 & $0.80(0.54-1.11)$ & $0.69(0.36-1.18)$
\end{tabular}

Low

Medium

$\geq 32.0-<46.0$

$0.79(0.58-1.00)$

$0.75(0.46-1.06)$

$0.72(0.37-1.20)$

High

$0.58(0.28-1.00)$

$0.69(0.35-1.17)$

$0.76(0.36-1.50)$

$\S$ Values are ORs $(95 \% \mathrm{CI})$ derived from models described above based on a smoothed dose-response analysis with tertiles of plasma vitamin $\mathrm{C}$ and dietary intake of red and processed meats. $95 \% \mathrm{CI}$ were assessed using a bootstrap sampling procedure. 